\title{
"Preference pattern of Investors in Stock Market-A case study of Investors in North Karnataka Region"
}

\author{
Amit B. Mirji ${ }^{1}$, Dr. Prashantha C. ${ }^{2}$ \\ ${ }^{1}$ (Research Scholar, Jain University, Bengaluru. India) \\ ${ }_{2}^{2}$ (Professor, Dept of Management Studies, SDM College of Engg \& Technology, Dharwad. India)
}

\begin{abstract}
Investors in the stock market in the study area have exhibited some significant trends regarding their preferences for investment. The study has covered 600 selected investor-respondents consisting of 482 male investors and 118 female investors in selected district head quarters of North Karnataka region. The major socio-economic profile of the respondents related to their sex, age categories, educational status, occupation, income groups and duration of experience in stock market. Majority of male investors seem to have preference for 'Large' and 'Midcaps' for investments while all the selected female respondents' investors have preferred 'small caps'. Preference for large and mid caps is more pronounced among majority of respondent investors with different socio-economic profiles like age, education, occupation, income and stock market experience. Male investors have exhibited more aggressive and risk assuming behaviour while female investors have indicated risk aversion approach.
\end{abstract}

Keywords: Investment, preferences, midcaps, small caps

\section{Introduction}

Preference pattern of male and female respondents and respondents with different socio-economic characteristics has been influenced by variations in their investment behaviours. The factors influencing their investment preference are the result of the behavioural biases found among the investors in general. The present study is an attempt to identify the preference of investors in stock market in the study areas of North Karnataka. The three options of preferences viz large cap, mid cap and 'small cap' have been studied covering a sample of 600 respondent investors in the study area.

\section{Analysis of the Responses of Investors}

The study covered selected district head quarters in North Karnataka region. The total number of 600 respondents' investors comprising of 482 male and 118 female have been covered by the study. The responses have been obtained through a structured questionnaire administered to the respondents. The responses are analysed relating to the investment preferences of male and female investors and investors with different socio and economic characteristics viz Age, Educational studies, Occupational status, Annual Income and Years of experience in stock market trading. The preference pattern of male and female respondent investors in the stock market avenues indicates wide and substantial differences. Maximum of 267 male investors (55.39\%) preferred "Large Cap" for their investment followed by 213 male respondent investors (44.19) indicated preference for "Mid Cap" while a very small number of 2 male respondent investors (0.41\%) were interested in investing their money in "Small Cap".

All the 118 female investors $(100 \%)$ indicated their preference for "Small Cap" for investment. The preference pattern indicates the wide difference in the perceptions of investors regarding the risks and their financial limitations of the male and female investors. Male investors are found to be more aggressive and risk assuming whereas female investors appear to be more conservative and risk aversion type in their investment activities.

Majority of 189 respondent investors (47\%) preferred 'large cap' followed by 13 investors (32.75\%) preferring 'Mid Cap' and 80 respondents (20\%) preferring "Small Cap" belonging to the age group of 31-40 Years. Majority of 74 investors in the age group of 41-50 years preferred "Mid Cap" followed by 50 investor's preferring 'Large Cap' and 17 investors preferring "Small Cap". In the younger age group of less than 30 years majority of 19 investors preferred "Small Cap" followed by 18 investors preferring 'Large Cap' and only 4 investors preferring preferred youth full investors have shown greater preference for large cap and Midcap. Similar is the trend of preference for investment in case of investors belonging to higher age group of 41-50 years. In the younger age group of 30 years or less smaller number of 19 investors preferred 'Small Cap', 18 investors' preferred 'large cap' and 4 investors preferred 'Mid Cap'. Similarly in the advanced age group 10 investors preferred 'Large Cap' and 4 investors each preferred 'Mid Cap' and "Small Cap". It is evident that there is a greater preference for 'Large' and 'Mid' cap among youthful and middle aged number of 400 and 141 respondent investors in these two age groups indicated their preference for investment. 
Among the investors with Graduate and Post-Graduate education there is greater preference for investment in 'Large' and 'Medium' Cap. A smaller number of investors with undergraduate level of education and those with doctorate degree preferred "Large" and "Medium" Cap for investment. The responses indicate that preference for investment in 'Large' and "Mid" cap is more pronounced among investors with higher education

A similar trend of greater preference for 'Large' and 'Mid' caps is found among majority of investors belonging to Business and employment occupations. Preferences for 'Large' 'Medium' and 'Small caps' for investment are expressed by a small number of respondent investors belonging to agriculture, home making and professional occupations. This trend indicates that businessmen and employees. Preferred large and medium cap due to their regular income and more liquidity compared to investors belonging to agriculture, home making and professionals.

The responses of majority of investors indicate a preference for 'large' and 'mid cap' for investment who had their annual income of $\mathrm{Rs}<=5,00,000$ followed by those with annual income of Rs $=5,00,001-10$, 00,000 and those with annual income of Rs $>=10,00,001$. A relatively lower number of respondents preferred investment in 'small cap'.

Preference for 'Large' and 'Mid' cap for investment is found among majority of respondent investors with 6-10 years and $11+$ years of experience of stock markets There is a lesser preference for 'mid' cap among investors with 1-5 years of experience of stock market and lesser preference for investment in 'small' cap among the few investors with 1- 5 years and 11+years of experience of stock market. The different groups of investors belonging to the three duration of experience do not reveal any uniform pattern of preference for investment in the 'Large', 'Mid' and 'Small' caps.

Preference of Investors for Investment in Large, Mid and Small caps

\begin{tabular}{|c|c|c|c|c|c|c|c|}
\hline Characteristics & Large cap & $\%$ & Mid cap & $\%$ & Small cap & $\%$ & Total \\
\hline \multicolumn{8}{|l|}{ Sex } \\
\hline Male & 267 & 55.39 & 213 & 44.19 & 2 & 0.41 & 482 \\
\hline Female & 0 & 0.00 & 0 & 0.00 & 118 & 100.00 & 118 \\
\hline \multicolumn{8}{|l|}{ Age groups } \\
\hline$<=30$ yrs & 18 & 43.90 & 4 & 9.76 & 19 & 46.34 & 41 \\
\hline 31-40yrs & 189 & 47.25 & 131 & 32.75 & 80 & 20.00 & 400 \\
\hline $41-50 \mathrm{yrs}$ & 50 & 35.46 & 74 & 52.48 & 17 & 12.06 & 141 \\
\hline$>=51 \mathrm{yrs}$ & 10 & 55.56 & 4 & 22.22 & 4 & 22.22 & 18 \\
\hline \multicolumn{8}{|l|}{ Educations } \\
\hline Undergraduate & 22 & 47.83 & 24 & 52.17 & 0 & 0.00 & 46 \\
\hline Graduate & 124 & 49.21 & 102 & 40.48 & 26 & 10.32 & 252 \\
\hline Post graduate & 117 & 39.80 & 85 & 28.91 & 92 & 31.29 & 294 \\
\hline Doctorate & 4 & 50.00 & 2 & 25.00 & 2 & 25.00 & 8 \\
\hline \multicolumn{8}{|l|}{ Occupations } \\
\hline Agriculture & 6 & 50.00 & 4 & 33.33 & 2 & 16.67 & 12 \\
\hline Business & 112 & 47.86 & 110 & 47.01 & 12 & 5.13 & 234 \\
\hline Employee & 133 & 42.90 & 95 & 30.65 & 82 & 26.45 & 310 \\
\hline Home worker & 0 & 0.00 & 0 & 0.00 & 12 & 100.00 & 12 \\
\hline Professional & 16 & 50.00 & 4 & 12.50 & 12 & 37.50 & 32 \\
\hline \multicolumn{8}{|l|}{ Annual income } \\
\hline$<=500000$ & 44 & 40.74 & 31 & 28.70 & 33 & 30.56 & 108 \\
\hline $500001-1000000$ & 195 & 45.88 & 157 & 36.94 & 73 & 17.18 & 425 \\
\hline$>=1000001$ & 28 & 41.79 & 25 & 37.31 & 14 & 20.90 & 67 \\
\hline \multicolumn{8}{|c|}{ Yrs on stock market } \\
\hline $1-5 y r s$ & 22 & 42.31 & 6 & 11.54 & 24 & 46.15 & 52 \\
\hline $6-10 y r s$ & 187 & 45.06 & 148 & 35.66 & 80 & 19.28 & 415 \\
\hline $11+\mathrm{yrs}$ & 58 & 43.61 & 59 & 44.36 & 16 & 12.03 & 133 \\
\hline Total & 267 & 44.50 & 213 & 35.50 & 120 & 20.00 & 600 \\
\hline
\end{tabular}

Table: Comparison of different characteristics with by chi-square test

\begin{tabular}{|l|c|c|}
\hline Characteristics & Chi-square & p-value \\
\hline Sex & 587.5520 & $0.0001^{*}$ \\
\hline Age groups & 43.3380 & $0.0001^{*}$ \\
\hline Educations & 51.9470 & $0.0001^{*}$ \\
\hline Occupations & 101.9400 & $0.0001^{*}$ \\
\hline Annual income & 10.0900 & $0.0390^{*}$ \\
\hline Yrs on stock market & 33.5810 & $0.0001^{*}$ \\
\hline
\end{tabular}

$* \mathrm{p}<0.05$ 
"Preference pattern of Investors in Stock Market-A case study of Investors in North Karnataka..

\section{Statistical Significance}

1. The association between sex and type of Cap is found to be statistically significant (Chisquare $=587.55, \mathrm{p}=0.0001$ ) at $5 \%$ level of significance.

2. A significant association between age groups and types of Cap is found to be statistically significant (Chisquare $=43.33, \mathrm{p}=0.0001$ ) at $5 \%$ level of significance.

3. The difference between education and types of square $=51.94, \mathrm{p}=0.0001$ )at $5 \%$ level of significance.

4. The association between annual income and type of Cap is found to be statistically significant (Chisquare $=101.94, \mathrm{p}=0.0001$ ) at $5 \%$ level of significance.

5. A significant association between annually income and type of Cap is found to be statistically significant (Chi-square $=10.09, \mathrm{p}=0.0390)$ at $5 \%$ level of significance.

6. Lastly, a significant association was observed between years on stock market and type of Cap is found to be statistically significant (Chi-square $=33.58, \mathrm{p}=0.0390)$ at $5 \%$ level of significance.

\section{Conclusions}

The study has revealed that preference for large and mid cap for investment is more pounced among majority male investors while all the female respondent investors have preferred to invest in 'small cap'. This indicates that male investors of stock market are aggressive and risk assuming whereas female investors appear to be more conservative and risk aversion type they have not preferred investment in 'large' and 'mid cap' but preferred small cap for investment. There is a general trend of preference for investment in large and mid cap by majority of respondent investors with different profile characteristics of age, education, occupation, income and experience in stock trading in the study area.

\section{References}

[1]. Chandra Abhijeet (2008)-Decision Making in the stock market-Incorporating psychology with Finance -Department of commerce and Business studies-New Delhi.

[2]. Chira Inga, Adams Michael and Thornton Barry (2008)- Behavioural Bias within. The Decision Making process -Journal of Business and Economic Research 6(8); 11-20.

[3]. Mehran Nik, Muham mad Nik, Ismail Nuraz Leena (2008)- Investdment Decision Behaviour- Faculty of Business Management Mara University of Technology Malaysia.

[4]. Hoffman, Arivd O,I, Shefrin Hersh and Pnnings Joost MF (2010)-Behavioural portfolio Analysis of Individual Investors- working paper Maastricht University and Junta Clara University .

[5]. Subrahmanyam Avanidhar (2007)- Behavioural Finance : A Review and Synthesis -European Financial Management 14(1):12-29.

[6]. Subash R(2012)-Role of Behavioural Finance in Portfolio Investment Decisions: Evidence from India-Master Thesis, Faculty of social sciences, charle University Prague, 2012

[7]. Pompian,M.(2011)-Behavioural Finance and wealth Management: How to Build optimal portfolios. That Account for Investor Bases, $2^{\text {nd }}$ Edition Wiley Finance publication, New Jersey 2011.

[8]. Statman .M. (1999)-Behavioural Finance : past Battles and Future Engaments ,Finance Analysis Journal vol 55 no 6

[9]. Statman .M. (2008)-what is Behavioural Finance Hand book of Finance - vol, II, John wily and sons Inc, New Jersey 2008.

[10]. Shefrin H (2008)-Beyand Greed and Fear: Understandung Behavioural Finance and the psychology of investing -New York.

[11]. Chandra .A.(2008)-Decision Making in Stock Market -Incorporating Psychology with Finance : Department of commerce and Business Studies.

[12]. Banerjee Arindam(2011)-Application of Behavioural Finance in Investment Decision -An overview -The Management Accountant 46(10).

[13]. Chen et al (2007) trading performance disposition Effect over confidence Representativeness Bias and experience of emerging Market Investors SSRN working paper 2007

[14]. Pompeian Michaud (2006) Behavioral finance and wealth management USA John Willer and sons 